\title{
The hypothalamic-pituitary-gonadal axis in mood disorders
}

\author{
Elizabeth A. Young, MD, $\mathrm{PhD}^{\mathrm{a}, *}$, \\ Ania Korszun, MD, $\mathrm{PhD}^{\mathrm{b}}$ \\ ${ }^{a}$ Department of Psychiatry and MHRI, University of Michigan, Ann Arbor, MI, USA \\ ${ }^{\mathrm{b}}$ Department of Psychological Medicine, University of Wales College of Medicine, \\ Heath Park, Cardiff, UK
}

Depression is known to be accompanied by abnormalities in the hypothalamic-pituitary-adrenal (HPA) axis and in the hypothalamic-pituitarythyroid axis. Little attention however, has been given to possible reproductive hormonal abnormalities in depression, despite suggestions that women are more vulnerable to depressive symptoms, particularly during times of rapid changes in gonadal steroid secretion. This article focuses on reproductive hormone status in two mood disorders: major depression and premenstrual syndrome (PMS).

\section{Differences in rates of depression in men and women}

Interest in reproductive hormones and depression date to the observations that depression is more common in women, specifically during times of changing ovarian steroids such as postpartum. Although it was known that more women seek treatment for major depression than men, initial studies focused on ascertaining if these sex differences were real or the result of assessment or treatment bias. The National Institute of Mental Health (NIMH) epidemiological catchment area (ECA) studies examining rates of major depression in the community at large $[49,66,68]$ made explicit that the greater incidence and prevalence of depression in women ( $8 \%$ to $9 \%$ for depression plus dysthymia) were real. The reasons for this higher incidence of major depression in women remains unclear. In an excellent, now classic

* Corresponding author. Department of Psychiatry and MHRI, University of Michigan, 205 Zina Pitcher Place, Ann Arbor, MI 48109, USA.

E-mail address: eayoung@umich.edu (E.A. Young).

The authors acknowledge the support of MH50030, MH01931 to EAY, and DE11972 to AK. 
review of sex difference in the prevalence of depression, Weissman and Klerman [87] described a number of possible "etiologies" for the greater prevalence of depression in women. None of the current psychological theories, however, account adequately for the greater prevalence of depressive disorders in women. Common to the various hypotheses about increased prevalence of depressive disorders in women is the concept that environmental factors contribute to the onset of major depression. Significant environmental risk factors include: loss of mother in childhood, stresses of family and job, lack of a close emotional relationship with one's spouse, marital discord, the presence of three children under the age of 14 in the home, sexual discrimination, and victimization/sexual abuse [87]. All of these factors may be conceptualized as psychosocial stressors that contribute to the onset of major depression in vulnerable individuals. The demonstration of overactivity in the main stress hormone system of the body, the HPA axis, in patients with major depression, lends credence to the hypothesis that stress contributes to the onset of major depression [11,70,74].

In addition to psychosocial stressors, biological, and genetic components contribute to depression. Genetic studies have demonstrated familial inheritance for both unipolar and bipolar depression $[23,38,89]$. Both of these disorders are primarily episodic and recurrent, with increasing frequency of major depressive episodes developing over time. In women with a previous episode of major depression, rapidly changing gonadal steroid concentrations, such as those occurring premenstrually or postpartum, mark particularly vulnerable times for the occurrence of depressive symptoms. Early studies by Reich and Winokur [65] suggested that the risk of a postpartum depressive episode in women with a previous episode of major depression is $30 \%$ versus $8 \%$ at other times. Studies by O'Hara et al. $[53,54]$ confirm that a history of depressive episodes increases the risk of both postpartum "blues" and postpartum major depression. Studies by Halbreich et al. [29,30] suggested that hormonal changes occurring premenstrually may affect mood. When not in a depressive episode, $62 \%$ of women with a history of past major depressive episodes reported the occurrence of premenstrual mood changes and biological symptoms typical of major depressive disorder, leading the authors to hypothesize that changes in gonadal steroid concentrations may contribute to depressive symptoms. Despite these various suggestions that reproductive hormones may play a role in mood disorders, the hypothalamic-pituitary-gonadal (HPG) axis has received little examination in depression, and the few existing studies have reached inconclusive findings, perhaps because they have tended to include men with pre- and postmenopausal women in the data analysis, rather than analyzing these groups separately. In their 1977 review on sex differences in depression, Weissman and Klerman [87] noted that "no study could be located that correlated clinical state with female endocrines, utilizing modern endocrinological methods or sensitive quantitative hormonal assays." This only recently has begun to change. 


\section{Stress and the reproductive axis}

Although the effects of stress on reproduction long has been recognized by clinicians, one of the earliest basic science reports of stress affecting fertility rates dates back to Christian's observations on population density and reproductive cycles in lemmings and voles and the link of the infertile periods cycles to adrenal steroids [16]. The isolation and sequencing of corticotropin releasing factor [85] coupled with observations of Knobil on inhibition of luteinizing hormone ( $\mathrm{LH}$ ) pulses in awake primates restrained in a primate chair gave further impetus to the investigation of the effects of stress on the reproductive axis [39]. To understand the impact of stress on this axis, this article presents a brief overview of the HPG axis and then describe the effects of stress on the reproductive axis.

The HPG axis, which regulates gonadal steroid production, is a multiple level hormonal system involving brain and pituitary with feed forward and feedback elements. The secretion of the principal gonadal steroids, estrogen and progesterone, is governed by cyclic changes in ovarian follicular and corpus luteum development over the course of the menstrual cycle. Critical to the proper functioning and timing of the monthly hormonal cycle is the pulsatile secretion of gonadotropin-releasing hormone $(\mathrm{GnRH})$. GnRH secretion from the hypothalamus drives the secretion of $\mathrm{LH}$ and follicle stimulating hormone (FSH) from pituitary gonadotropes [17]. Estradiol exerts a negative feedback on FSH secretion and both negative and delayed positive feedback effects on LH secretion [36]. The change in estradiol feedback from negative to positive late in the follicular phase is complemented by rising progesterone and results in the midcycle surge in LH necessary for ovulation.

Gonadal steroids exert negative feedback effects on the amplitude and frequency of GnRH pulses and through this mechanism (in addition to direct actions on the pituitary) inhibit the secretion of LH and FSH. Circadian changes in LH secretion are not as prominent as those of the HPA axis [35].

Early studies with corticotropin-releasing factor (CRF) by Rivier indicated clear inhibitory effects of central CRF injection on GnRH secretion and subsequent studies in a number of species have continued to document inhibitory effects of CRF on GnRH and LH secretion $[21,22,45,51,55,57]$ (Fig. 1). Additionally, central opioids, particularly $\beta$-endorphin, exert a tonic inhibition on GnRH secretion [21], and it appears that central CRH can regulate arcuate $\beta$-endorphin release. $\mathrm{CRH}$ is distributed widely in the brain and appears to mediate a number of the behavioral effects of stress, including anorexia and anxiety, and to initiate the hormonal cascade of the HPA axis. The effects of CRH on GnRH secretion may be both direct and indirect: $\mathrm{CRH}$ neurons can synapse with GnRH neurons [45], and $\mathrm{CRH}$ can function as a secretagogue for $\beta$-endorphin secretion from the arcuate $\beta$-endorphin system [52]. These inhibitory effects of gonadal steroids, $\beta$-endorphin and CRH appear to result from central actions of these hormones (i.e., actions in the brain). 


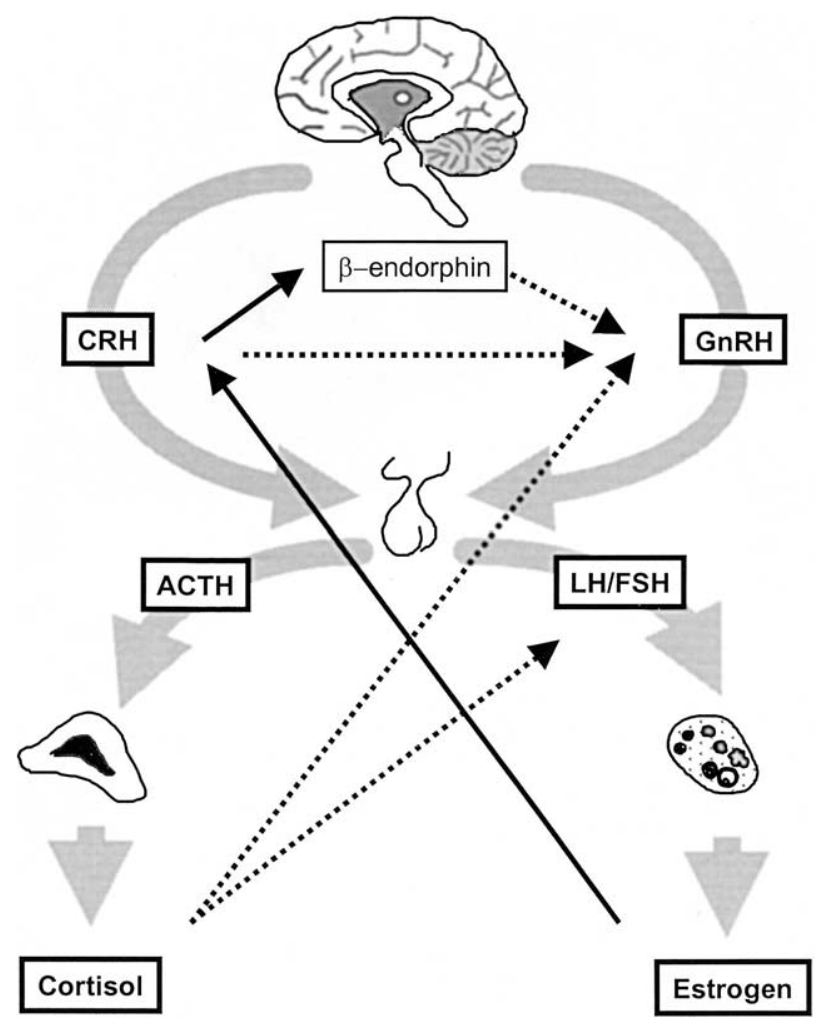

Fig. 1. Interactions between HPA and hypothalamic-adrenal-ovarian axes. Solid line= stimulatory actions; dotted line $=$ inhibitory actions. From Young EA, Korzsun A. Psychoneuroendocrinology of depression: hyphothalamic-pituitary-gonadal axis. Psych Clin N Am 1998;21:313; with permission.

In addition to the clear inhibition of $\mathrm{GnRH}$ secretion by $\mathrm{CRH}$, older studies suggested that peripheral elements of the HPA axis may affect LH secretion. Several studies have demonstrated that corticotropin (ACTH) administration reduces the increase in serum LH concentrations following ovariectomy or orchidectomy $[46,80]$. This effect depends on the presence of the adrenal, and may involve adrenal production of gonadal steroids which is regulated by ACTH [61]. Glucocorticoids also may exert inhibitory effects on GnRH secretion or $\mathrm{LH}$ responsiveness to $\mathrm{GnRH}$, including direct effects of cortisol on the gonadotrope [67,83]. A glucocorticoid responsive element (GRE) is present on the GnRH gene, providing the potential for glucocorticoids to modulate $\mathrm{GnRH}$ gene expression and this has been observed in several hypthalamus-derived cell lines [3,15]. Diminished LH response to $\mathrm{GnRH}$ following long-term prednisolone treatment, has been found in women [75]. Furthermore, in women with Cushings' Disease, menstrual cycle irregularity correlate with hypercortisolemia [41]. Saketos et al. 
[76] observed slowing of LH pulse frequency with hydrocortisone infusion, although other investiators have not confirmed this [77]. $\beta$-Endorphin secreted by pituitary corticotropes also may be able to affect GnRH secretion by way of actions on the median eminence. In a series of studies by Ferin et al. in rhesus monkeys, peripherally administered CRH decreased LH pulse frequency and integrated LH secretion over several hours [24, $25,55,90,91]$. This effect involved a glucocorticoid regulated endogenous opioid system, suggesting the involvement of the anterior pituitary proopiomelanocortin (POMC) system.

\section{Hypothalamic control of gonadotropins}

The pulsatile secretion of GnRH is driven by a pulse generator in the arcuate nucleus of the hypothalamus [39]. The structural characteristics of individual pulses of $\mathrm{GnRH}$ and the time series pattern of their secretion controls frequency, amplitude and most likely nature of LH secretory episodes. Studies in sheep examining GnRH secretion into hypophyseal portal blood demonstrate a clear one to one correspondence between GnRH secretory pulses in portal blood and LH secretory pulses in peripheral circulation [17]. This pulsatile pattern of GnRH secretion is critical for the control of serum LH, FSH, and ovulation. Indeed, continuous administration of GnRH in a nonpulsatile pattern results in suppression of ovulation as effectively as inadequate secretion of GnRH. Studies in primates with arcuate lesions have demonstrated that administration of GnRH pulses in frequencies that are too fast or too slow result in low serum concentrations of LH [5]. Because access to the hypophyseal portal circulation in women cannot be gained to measure actual GnRH secretory dynamics, LH secretory pulses in the peripheral circulation are used as the marker of GnRH secretory pulses. In humans, the follicular phase of the menstrual cycle is characterized by reasonably constant amplitude LH pulses every 1 to 2 hours [62]. During the luteal phase, pulse amplitude becomes much more variable, and pulse frequency decreases to one pulse every 2 to 6 hours.

\section{Similarities among depression, exercise-induced amenorrhea, anorexia nervosa and hypothalamic amenorrhea}

Major depression is accompanied by increased cortisol secretion, resistance to the negative feedback effects of cortsiol and dexamethasone, and a decreased ACTH response to CRH administration [12,27,30,34,42,58,70, $93,95]$. In addition to depression, several other disorders of women have been described with HPA axis dysregulation similar to that seen in depressed women. These include exercise-induced amenorrhea, anorexia nervosa, and hypothalamic amenorrhea. In these syndromes, amenorrhea is a primary presenting problem. Hypercortisolemia also has been observed, indicating overactivity of the HPA axis $[7,13,32,44,82,86]$. In all three 
syndromes $\mathrm{CRH}$ has been used as a challenge to evaluate pituitary and adrenal function. The response to $\mathrm{CRH}$ is similar to that seen in depressed patients (i.e. diminished ACTH or cortisol responses), suggesting that high baseline cortisol exerts negative feedback effects on the hormonal responses to $\mathrm{CRH}$ $[9,26,33]$. In anorexia nervosa, the hormonal abnormalities in HPA and HPG axes are secondary to weight loss. Weight restriction and low body weight also is observed in exercise-induced amenorrhea, and low body weight has been reported in hypothalamic amenorrhea. Even relatively mild degrees of weight loss in normal weight or obese subjects can lead to disturbances in both axes as manifested by resistance to dexamethasone and by disturbances in menstrual regularity or amenorrhea $[8,18,59,73]$. Consequently, these amenorrheic syndromes present with evidence of weight loss, increased HPA axis activation, disrupted HPG functioning, and amenorrhea.

In common with the findings in these syndromes, weight loss and HPA axis overactivity are frequent findings in major depression, and increased cerebrospinal fluid levels of $\mathrm{CRH}$ have been reported in both depression and anorexia nervosa $[37,50]$. The well-demonstrated inhibitory effects of central CRH on GnRH secretion suggest that if peripheral HPA axis overactivity reflects central CRH overactivity, then HPA axis disturbances should be accompanied by disturbances in GnRH secretion. The influence of this presumed CRH overactivity on gonadal hormone secretion only recently has been evaluated critically in men and women with major depression.

The disturbances in GnRH secretion in anorexia nervosa and hypothalamic amenorrhea have been evaluated primarily by examining the characteristics of LH pulsatile activity. In anorexia nervosa, LH secretory patterns may revert to prepubertal levels of low, nonpulsatile secretion, or to a pubertal pattern of entrainment of LH secretion to the sleep cycle. Studies by Reame et al. on women with hypothalamic amenorrhea demonstrated that LH secretion in the follicular phase is slowed to the rate normally observed during the luteal phase [62]. In these individuals, LH and FSH responses to $\mathrm{GnRH}$ appear normal, indicating that the reduced pulse frequency is not secondary to pituitary changes but presumably because of changes in the GnRH pulse generator.

\section{Reproductive hormone studies in major depression}

A number of older studies of reproductive hormones in depression $[1,2,4,6,10,19,20,43,69,72,84,88]$ examined mean LH levels but are problematic for interpretation, since they are based on isolated measurements in a dynamic system. Furthermore, these studies included men, premenopausal women in both follicular and luteal phases, and postmenopausal women without examining the influences of these factors separately. During the luteal phase, LH pulses are large (amplitudes of 1 to $10 \mathrm{mIU} / \mathrm{mL}$ ) and infrequent (e.g., once every 6 hours). During the follicular phase, LH pulses are frequent but of smaller amplitude ( 2 to $5 \mathrm{mIU} / \mathrm{mL}$ ). Finally, postmenopau- 
sally, absolute concentrations of $\mathrm{LH}$ can reach 30 to $50 \mathrm{mIU} / \mathrm{mL}$. Furthermore, "average LH concentrations" miss a substantial portion of the information contained in this system, in which frequency modulation plays a critical role in the normal functioning of the axis, influencing both regulation of ovulation and subsequent ovarian hormone secretion.

In depression, response to GnRH has been assessed by three groups. Using a high dose of GnRH $(250 \mu \mathrm{g})$, Winokur et al. reported a normal LH and FSH response to GnRH in a group of male and female depressed patients that included both pre- and postmenopausal women [88]. Measurements of LH concentration in a single blood sample revealed lower basal LH concentrations in depressed than in control postmenopausal women. The sample size was not large enough to analyze the baseline or response to GnRH stimulation data separately for men and pre- versus postmenopausal women. Unless GnRH secretion is markedly reduced, however, an abnormal response to GnRH would not be expected, since altered GnRH secretion is a central, not peripheral, phenomenon. Brambilla et al. [10] used a lower dose of GnRH $(150 \mu \mathrm{g})$ to examine $\mathrm{LH}$ response to $\mathrm{GnRH}$ in 15 pre- and 32 postmenopausal depressed women. They noted a decreased LH response to GnRH in both groups. Measurement of serum LH in four samples drawn over the course of an hour again demonstrated lower baseline LH concentrations in postmenopausal depressed women than in their matched controls. Studies by Unden et al. [84], again examining depressed patients of both sexes and not analyzed separately, observed no change in baseline or GnRH-stimulated LH and FSH secretion.

Recent studies have begun using modern understanding of reproductive hormones to examine LH pulsatility and other reproductive hormone levels in depression. O’Toole and Rubin [56] examined mean LH and FSH levels in depressed women and menstrual status but not phase-matched control women every half hour over 16 hours, and found normal mean levels of LH and FSH. A study by Meller et al. [47], examining LH pulsatility in 10 depressed follicular phase women and 13 control women found no difference in number of LH pulses over an 8 hour period, although significantly increased LH amplitude and LH area under the curve were observed in depressed women. Schweiger et al. [81] examined pulsatile LH secretion and mean LH, FSH, and testosterone in depressed men and normal controls using frequent sampling methods. They found normal LH pulsatility and normal mean LH and FSH but decreased mean testosterone in men with major depression, leading them to conclude that gonadal function may be disturbed in men with a depressive episode.

The authors recently completed a study of 25 premenopausal depressed women (Fig. 2) [93]. Each woman was matched individually on age and menstrual cycle day to a healthy normal control woman. Samples were drawn every 10 minutes for 12 hours, and data were analyzed for LH pulsatility, mean FSH, estradiol, and progesterone. Twelve patients and their matched controls were studied in the follicular phase and 13 in the luteal phase. The 


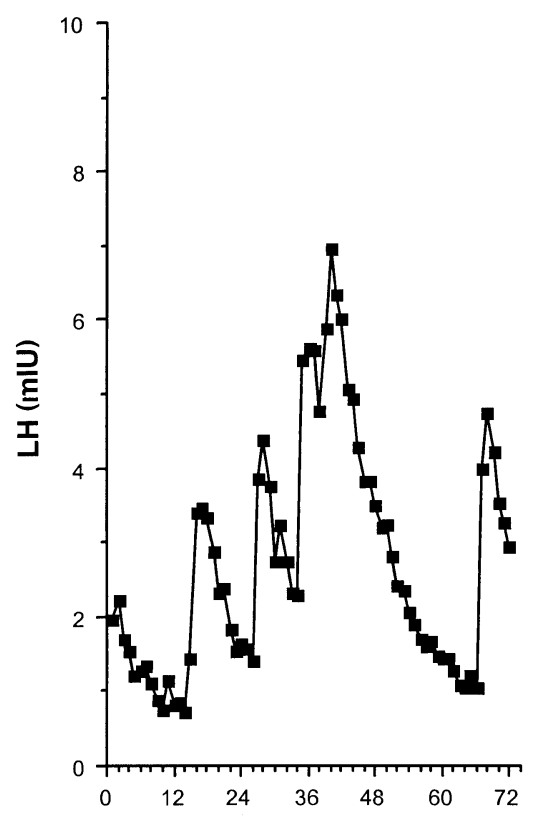

A

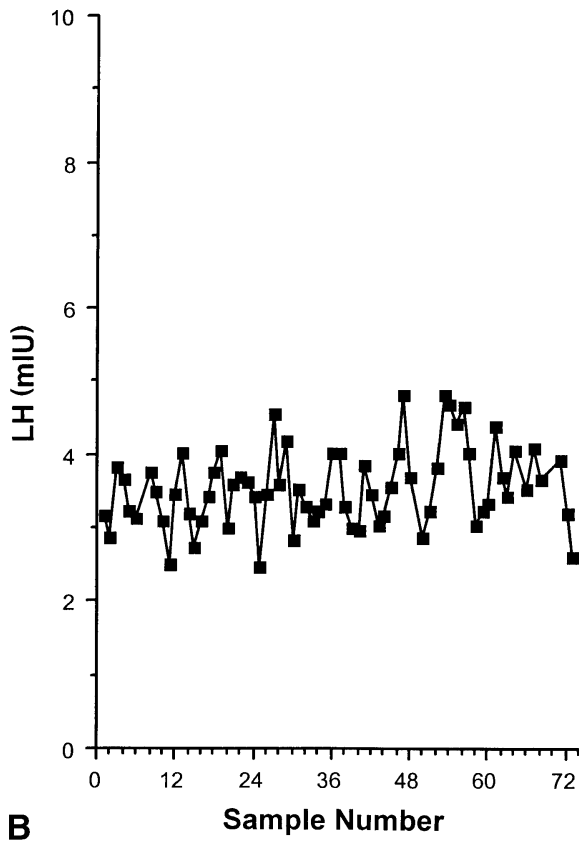

Fig. 2. (A) Normal LH profile during luteal phase as defined by 10 minute sampling over 12 hours. (B) Normal LH profile during follicular phase as defined by 10 minute sampling over 12 hours.

authors found the expected follicular-luteal phase differences in mean FSH, and estradiol, and LH pulse amplitude, pulse half-life, and pulse number. The authors found no significant difference between patient and controls on any measure of LH except the half-life of $\mathrm{LH}$, which was significantly shorter in patients than in controls. Furthermore, they found decreased mean estradiol in the follicular phase in depressed women. Given the normal progesterone levels in the luteal phase in depressed women, however, there appears to be no ovulatory defect in depressed women. These data, combined with the previous data of Schweiger [81] and Meller [47] suggest that the critical neuronal circuits controlling GnRH secretion and GnRH pulsatility are normal in depressed women. Furthermore, there was no relationship between mean 24 hour cortisol and any LH parameter in the study, despite the presence of hypercortisolemia in some subjects. Likewise, the depressed subjects in the reports by Schweiger et al. [81] demonstrated activation of the HPA axis as reflected by increased cortisol secretion. Still, there may be a gonadal defect in major depression leading to lower testosterone in depressed men and lower estradiol in follicular phase depressed women. Alternatively, it may be that individuals with low estradiol are more vulnerable to major depression. (in men, testosterone is converted to estradiol in vivo and exerts a number of effects through estradiol receptors) (Fig. 3). 


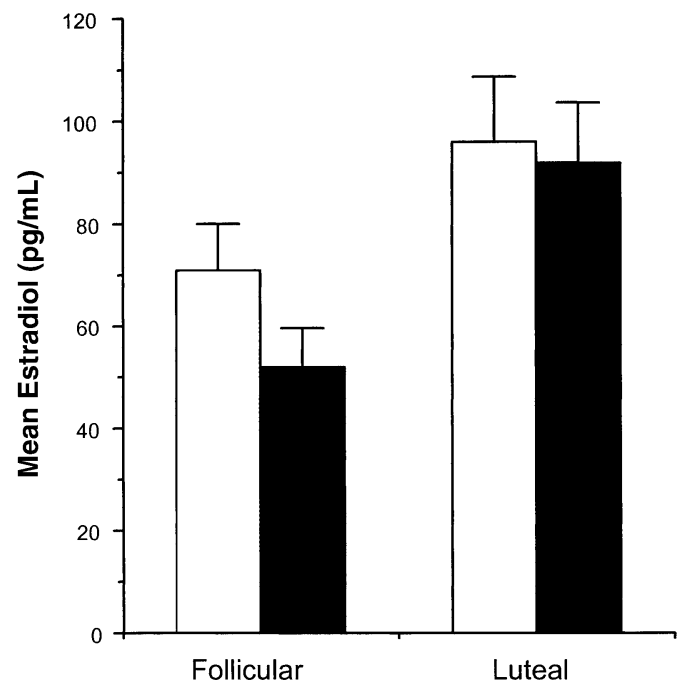

Menstrual Phase

Fig. 3. Plasma estradiol in untreated depressed women. Open bar $=$ control; solid bar $=$ depressed.

\section{PMS and ovarian hormones}

One of the most well-studied mood disorders with respect to the influence of ovarian steroids on mood is PMS or late luteal phase disorder (DSMIIIR). The experience of researchers in the field is uniform in that many more women report significant variations in mood premenstrually in retrospective reports than are found to have symptoms with prospective studies. Thus, it is necessary to define the study population carefully and limit both endocrine investigations and treatment to women with clear luteal phase depressive symptoms who are well during the follicular phase. Studies by Reame et al. [64] used state-of-the art assays and optimal sampling frequency to investigate LH, FSH, pulse frequency, and amplitude in follicular, mid- and late luteal phases of the menstrual cycle, and examine estradiol and progesterone levels at these three time points. At no time were estradiol and progesterone different between women with PMS compared with controls. LH pulse frequency was also similar in both groups with parallel changes across the menstrual cycle. Mean FSH was higher in the PMS group at mid luteal phase, although the meaning of an isolated change in FSH is hard to explain. Thus, the data do not suggest an alteration in GnRH secretion or ovarian steroids in women with PMS. Despite the absence of documented abnormalities in these hormone systems, a number of studies suggest that manipulations of ovarian steroids can improve the symptoms.

One of the best documented effective treatments is elimination of menstrual cycling with leuprolide, a GnRH agonist, that improves mood. 
Because this also leads to hypoestrogenism, which affects bone density and cardiovascular disease, it is necessary to add both steroid hormones. In the study by Mortola et al. [48], just the addition of a placebo with the suggestion that it might make mood symptoms worse, caused a significant worsening in mood symptoms. Still, addition of conjugated equine estrogen with or without medroxyprogesterone acetate (MPA) while still on leuprolide did not lead to a relapse in depressive symptoms. Not all studies have agreed that progesterone can be added back without significant worsening of symptoms. In fact, this may depend upon the dose of progesterone, since higher doses cause relapse and administration of oral contraceptives which have more potent progesterone than MPA exacerbate PMS [31]. Although it appears that some aspect of menstrual cycling may exacerbate mood problems in vulnerable women, whether this extends to women with major depression is unclear. Finally, progesterone has been used for the treatment of PMS despite its documented lack of effectiveness. Although clearly not effective, it does not appear to worsen mood symptoms [92].

Because it was believed that the symptoms of PMS are related to delayed effects of progesterone on mood, several studies have investigated the effects of RU486, a progesterone antagonist on mood symptoms. In studies by Schmidt et al. [79], the creation of an artificial follicular phase during the second half of the menstrual cycle by the use of RU486 plus human chorionic gonadotropin did not result in a reduction of mood symptoms. Likewise blockade of progesterone's action led to early menses with depressive symptoms still occurring. Likewise, the study by Chan, et al. [14] using a randomized double blend placebo controlled cross-over design for 6 months showed no effectiveness of RU486 on mood symptoms. Thus, although generally believed that PMS is related to changes in CNS neurotransmitter systems caused by progesterone, the data did not support that progesterone blockade affects these mood symptoms. This led Rubinow and Schmidt [71] to propose that PMS is a cyclical mood disorder "entrained" to the menstrual cycle, rather than a disorder caused by changes in ovarian steroids.

\section{Ovarian steroids' effects on mood in major depression}

As reviewed previously, the changes in sex steroids in major depression are small, it is possible, however, that depressed women may be more resistant to the beneficial effects of ovarian steroids on mood. An early report by Prange et al. [60], suggested that estrogen could act to augment the response to antidepressants. Many clinicians routinely provide estrogen supplementation to postmenopausal depressed women to improve mood, although even this practice has not been documented in placebo controlled trials. Only recently has antidepressant response been examined by sex and menopausal status to determine if ovarian steroids influence treatment response. In a large multicentered collaborative study comparing sertraline with imipramine [40], it 
was observed that premenopausal women showed a greater drop out rate because of side effects in the imipramine group, while men and postmenopausal women dropped out more on the sertraline. There was a trend level finding that premenopausal women responded better to sertraline than imipramine while postmenopausal women responded better to imipramine. Additionally, women on oral contraceptives responded even better to he sertraline than premenopausal women. These data further suggest the need for placebo controlled trials of estrogen augmentation to depression.

\section{Summary}

This article has demonstrated that stress and HPA axis activation affect the reproductive axis. Despite similarities in the HPA axis picture between women with major depression and those with hypothalamic amenorrhea and exercise or nutritional amenorrhea, no abnormalities in LH secretion have been documented in major depression. Lower estradiol in the follicular phase in depressed women and lower testosterone in depressed men however, have been observed [81,92]. Although PMS would appear to be the best candidate for a mood disorder associated with abnormalities in reproductive hormones, no abnormalities in $\mathrm{LH}$, estradiol or progesterone have been documented in PMS either [62]. Similarly, blockade of progesterone appears to be ineffective as a treatment for PMS [79]. Complete elimination of monthly cycling with leuprolide improves mood, however. No published studies have examined women with major depression to determine whether leuprolide will exacerbate or improve depressive symptoms. Some studies suggest beneficial effects of estrogen on mood in postmenopausal women, but no placebo controlled studies have explored estrogen augmentation in the treatment of major depression in either post- or premenopausal women, although estrogen is beneficial in women with perimenopause-related mood disorders [78].

\section{References}

[1] Altman N, Sachar EJ, Gruen PH, Holpen JS, EtoS Reduced plasma LH concentration in postmenopausal depressed women. Psychosom Med 1975;37:274-83.

[2] Amsterdam JD, Winokur A, Caroff S, Snyder P. Gonadotropin release after administration of GnRH in depressed patients and healthy volunteers. J Affect Disord 1981;3:367-80.

[3] Attardi B, Tsujii T, Friedman R, Zeng Z, Roberts JL, Dellcrode T, Pfaff DW, Chandran UR, Sullivan MW. Glucocorticoid repression of gonadotropin-releasing hormone gene expression and secretion in morphologically distinct subpopulations of GT1-7cells. Mol Cell Endocrinol 1997;131:241-55.

[4] Baumgartner A, Graf KJ, Kurten I, Meinhold H, Scholz P. Neuroendocrinological investigations during sleep deprivation in depression. I. Early morning levels of thyrotropin, TH, cortisol, prolactin, LH, FSH, estradiol, and testosterone. Biol Psychiatry 1990;28:556-68.

[5] Belchetz PE, Plant TM, Nakai Y. Keogh EJ, Knobil E. Hypophyseal responses to continuous and intermittent delivery of gonadotropin-releasing hormone. Science 1978;202: 631-33. 
[6] Benkert O. Studies on pituitary hormones and releasing hormones in depression and sexual impotence. Prog Brain Res 1975;42:25-36.

[7] Berga SL, Mortola JF, Girton L, Suh B, Laughlin G, Pham P, Yen SS. Neuroendocrine aberrations in women with functional amenorrhea. J Clin Endocrinol Metab 1989;68:301-8.

[8] Berger M, Pirke K, Doerr P, Krieg JC, Van Zessen D. Influence of weight loss on the dexamethasone suppression test. Arch Gen Psychiatry 1983;40:585-6.

[9] Biller BM, Federoff HJ, Koenig JI, Klibanski A. Abnormal cortisol secretion and responses to corticotropin-releasing hormone in women with hypothalamic amenorrhea. J Clin Endocrinol Metab 1990;70:311-17.

[10] Brambilla F, Maggioni M, Ferrari E, Scarone S, Catalano M. Tonic and dynamic gonadotropin secretion in depressive and normothymic phases of affective disorders. Psychiatry Res 1990;32:229-39.

[11] Carroll BJ, Curtis GC, Mendels J. Neuroendocrine regulation in depression I. Limbic system-adrenocortical dysfunction. Arch Gen Psychiatry 1976;33:1039-44.

[12] Carroll BJ, Feinberg M, Greden JF, Tarika J, Albala AA, Haskeh RF, James NM, Kronfol Z, Lohr N, Steiner M, de Vigne JP, Young EA. A specific laboratory test for the diagnosis of melancholia: Standardization, validation, and clinical utility. Arch Gen Psychiatry 1981;38:15-22.

[13] Casanueva FF, Borras CG, Burguera B, Muruais C, Fernandez M, Devesa J. Steroids and neuroendocrine function in anorexia nervosa. J Steroid Biochem Molec Biol 1987;27: $635-40$.

[14] Chan AF, Mortola JF, Wood SH, Yen SS. Persistence of premenstrual syndrome during low-dose administration of the progesterone antagonist RU 486. Obstet Gynecol 1994;84: $1001-5$.

[15] Chandran UR, Attardi B, Friedman R, Oong KW, Roberts JL, DeFranco DB. Glucocortoid receptor-mediated repression of gonadotropin-releasing hormone promoter activity in GT1 hypothalamic cell lines. Endocrinology 1994;134(3):1467-74.

[16] Christian JJ. Population density and reproductive efficiency. Biol Reprod 1971;4:248-94.

[17] Clarke IJ, Cummins JT. The temporal relationship between gonadotropin releasing hormone $(\mathrm{GnRH})$ and leutenizing hormone $(\mathrm{LH})$ secretion in ovariectomized ewes. Endocrinology 1982;111:1737-9.

[18] Edelstein CK, Roy-Byrne P, Fawzy FI, Dornfeld L. Effects of weight loss on the dexamethasone suppression test Am J Psychiatry 1983;140:338-41.

[19] Ettigi PG, Brown GM, Seggie JA. TSH and LH responses in subtype of depression. Psychosom Med 1979;41:203-8.

[20] Ettigi PG. Anterior pituitary function in depression. In: Bhatnagar AS, (ed): The anterior pituitary gland. New York: Raven Press; 1982. p. 405-414.

[21] Ferin M, Vande Wiele R. Endogenous opioid peptides and the control of the menstrual cycle. Eur J Obstet Gynecol Reprod Biol 1984;18:365-73.

[22] Gambacciani M, Yen SS, Rasmussen DD. GnRH release from the mediobasal hypothalamus: In vitro inhibition by corticotropin-releasing factor. Neuroendocrinology 1986; 43:533-6.

[23] Gershon ES, Dunner DL, Goodwin FK. Toward a biology of affective disorders. Arch Gen Psychiatry 1971;25:1-5.

[24] Gindoff P, Xiao E, Luckhaus J, Ferin M. Dexamethasone treatment prevents the inhibitory effect of corticotropin-releasing hormone $(\mathrm{CRH})$ on gonadotropin release in the primate. Neuroendocrinology 1989;49:202-6.

[25] Gindoff PR, Ferin M. Endogenous opioid peptides modulate the effect of corticotropin releasing factor on gonadotropin release in the primate. Endocrinology 1987;121:837-42.

[26] Gold PW, Gwirtsman H, Avgerinos P, Nieman LK, Gallucci WT, Kaye W, Jimerson D, Ebert M, Rittmaster R, Loriaux DL, Chrousous GP. Abnormal hypothalamic pituitary adrenal function in anorexia nervosa: pathophysiological mechanisms in underweight and weight corrected patients. N Engl J Med 1986;314:1335. 
[27] Gold PW, Loriaux DL, Roy A, Kling MA, Calabrese JR, Kellner CH, Nieman LK, Post RM, Picker D, Gallucci W. Response to corticotropin-releasing hormone in the hypercortisolism of depression and Cushing's disease. N Engl J Med 1986;314:1329-35.

[28] Halbreich U, Asnis GM, Schindledecker R, et al. Cortisol secretion in endogenous depression I. Basal plasma levels. Arch Gen Psychiatry 1985;42:909-14.

[29] Halbreich U, Endicott J, Goldstein S, Nee J. Premenstrual changes and changes in gonadal hormones. Acta Psychiatr Scand 1986;74:576-86.

[30] Halbreich U, Vital-Herne J, Goldstein S, Zander K. Sex differences in biological factors putatively related to depression. J Affect Disord 1984;7:223-33.

[31] Hammaback S, Backstron T, Holst J, von Schoultz B, Lyrenas S. Cyclical mood changes as in premenstrual tension syndrome during sequential estrogen-progestogen postmenopausal replacement therapy. Acta Obstet Gynecol Scand 1985;64:393-7.

[32] Hohtari H, Elovainio R, Salminen K, Laatikainen T. Plasma corticotropin-releasing hormone, corticotropin, and endorphins at rest and during exercise in eumenorrheic and amenorrheic athletes. Fertil Steril 1988;50:233-8.

[33] Hohtari H, Salminen-Lappalainen K, and Laatikainen T. Response of plasma endorphins, corticotropin, cortisol, and luteinizing hormone in the corticotropin-releasing hormone stimulation test in eumenorrheic and amenorrheic athletes Fertil Steril 1991;552:276-280.

[34] Holsboer F, Bardeleden U, Gerken A, et al. Blunted corticotropin and normal cortisol response to human corticotropin-releasing factor in depression. N Engl J Med 1984; 311:1127.

[35] Jaffe RB, Plosker S, Marshall L, Martin MC. Neuromodulatory regulation of gonadotropin-releasing hormone pulsatile discharge in women. Am J Obstet Gynecol 1990;163: 1727-31.

[36] Karsch FJ, Foster DK, Bittman EL, et al. A role of estradiol in enhancing LH pulse frequency during the follicular phase of the estrous cycle of sheep. Endocrinology 1983;113:1333-9.

[37] Kaye WH, Gwirtsman HE, George DT, Ebert MH, Jimerson DC, Tomai TP, Chrouos GP, Gold PW. Elevated CSF levels of immunoreactive CRH in anorexia nervosa: Relationship to state of nutrition, adrenal function and intensity of depression. J Clin Endocrinol Metab 1987;64:203-8.

[38] Kendler KS, Kessler RC, Neale MC, Heath AC, Eaves LJ. The prediction of major depression in women: Toward an integrated etiological model. Am J Psychiatry 1993; 150:1139-1148.

[39] Knobil E. The GnRH pulse generator. Am J Obstet Gynecol 1990;163:1721-7.

[40] Kornstein SG, Schatzberg AF, Thase ME, Yenkers KA, McCullough JP, Keitner GI, Gelenberg AJ, Ryan CE, Hess AL, Harrison W, Davis SM, Keller MB. Gender differences in treatment response to sertraline versus imipramine in chronic depression. Am J Psychiatry 2000;157:1445-52.

[41] Lado-Abeal J, Rodriguez-Arnao J, Newell-Price JD, Perry LA, Grossman AB, Besser GM, Trainer PJ. Menstrual abnormalities in women with Cushings's disease are correlated with hypercortisolemia rather than raised circulating androgen levels. J Clin Endocrinol Metab 1988;83:3083-8.

[42] Linkowski P, Mendelwicz J, LeClercq R, et al. The 24-hour profile of ACTH and cortisol in major depressive illness. J Clin Endocrinol Metab 1985;61:429.

[43] Linnoila M, Lamberg BA, Rosberg G, Karonen SL, Welin MG. Thyroid hormones and TSH, prolactin and LH responses to repeated TRH and LRH injections in depressed patients. Acta Psychiatr Scand 1979;59:536-44.

[44] Loucks AB, Mortola JF, Girton L, Yen SS. Alterations in the hypothalamic-pituitaryovarian and the hypothalamic-pituitary-adrenal axes in athletic women J Clin Endocrinol Metab 1989;68:402-411.

[45] MacLusky NJ, Naftolin F, Leranth C. Immunocytochemical evidence for direct synaptic connections between corticotrophin-releasing factor (CRF) and gonadotrophin-releasing 
hormone $(\mathrm{GnRH})$-containing neurons in the preoptic area of the rat. Brain Res 1988; 439:391-5.

[46] Mann D, Jackson G, Bland M. Influence of adrenocorticotropin and adrenalectomy on gonadotropin secretion in immature rats. Neuroendocrinology 1982;34:20-6.

[47] Meller WH, Zander KM, Crosby RD, et al. Luteinizing hormone pulse characteristics in depressed women. Am J Psychiatry 1997;154:1545-5.

[48] Mortola JF, Girton L, Fischer U. Successful treatment of severe premenstrual syndrome by combined use of gonadotropin-releasing hormone agonist and estrogen/progestin. J Clin Endocrinol Metab 1991;72:252A-252F.

[49] Myers JK, Weissman MM, Tischler GL, et al. Six month prevalence of psychiatric disorders in three communities. Arch Gen Psychiatry 1984;41:959-67.

[50] Nemeroff CB, Widerlov E, Bisette G, et al. Elevated concentrations of CSF corticotropinreleasing-factor-like immunoreactivity in depressed patients. Science 1984;226:1342-4.

[51] Nikolarakis KE, Almeida OF, Herz A. Corticotropin-releasing factor (CRF) inhibits gonadotropin-releasing hormone $(\mathrm{GnRH})$ release from superfused rat hypothalami in vitro. Brain Res 1986;377:388-90.

[52] Nikolarakis KE, Almeida OF, Herz A. Inhibition of LH release by CRF may be partially mediated through hypothalamic beta-endorphin release. NIDA Res Monogr 1986;75:403-5.

[53] O'Hara MW. Social support, life events and depression during pregnancy and the puerperium. Arch Gen Psychiatry 1986;43:569-73.

[54] O'Hara MW, Schlecte JA, Lewis DA, et al. Prospective study of post-partum blues: biological and Psychosocial factors. Arch Gen Psychiatry 1991;48:801-6.

[55] Olster DH, Ferin M. Corticotropin-releasing hormone inhibits gonadotropin secretion in the ovariectomized rhesus monkey. J Clin Endocrinol Metab 1987;65:262-9.

[56] O'Toole SM, Rubin RT. Neuroendocrine aspects of primary endogenous depressionXIV. Gonadotropin secretion in female patients and their matched controls. Psychoneuroendocrinology 1995;20:603-12.

[57] Petraglia F, Sutton S, Vale W, et al. Corticotropin-releasing factor decreases plasma luteinizing hormone levels in female rats by inhibiting gonadotropin-releasing hormone release into hypophysial-portal circulation. Endocrinology 1987;120:1083-8.

[58] Pfohl B, Sherman B, Schlecte J, et al. Pituitary/adrenal axis rhythm disturbances in psychiatric patients. Arch Gen Psychiatry 1985;42:897-903.

[59] Pirke KM, Schweiger U, Lemmel W, et al. The influence of dieting on the menstrual cycle of young, healthy women. J Clin Endocrinol Metab 1985;60:1174-9.

[60] Prange AJ. Estrogen may well affect response to antidepressant. JAMA 1972;219:143-4.

[61] Putnam CD, Brann DW, Mahesh VB. Acute activation of the adrenocorticotropin-adrenal axis: Effect on gonadotropin and prolactin secretion in the female rat. Endocrinology 1991;128:2558-66.

[62] Reame NE, Marshall JC, Kelch RP. Pulsatile LH secretion in women with premenstrual syndrome (PMS): Evidence for normal neuroregulation of the menstrual cycle. Psychoneuroendocrinology 1992;2-3:205-13.

[63] Reame N, Sauder SE, Kelch RP, et al. Pulsatile gonadotropin secretion during the human menstrual cycle: evidence for altered pulse frequency of gonadotropin releasing hormone secretion. J Clin Endocrinol Metab 1984;59:328-37.

[64] Reame NE, Sauder SE, Case GD, et al. Pulsatile gonadotropin secretion in women with hypothalamic amennorhea: Evidence that reduced frequency of gonadotropin-releasing hormone secretion is the mechanism of persistent anovulation. J Clin Endocrinol Metab 1985;61:851-8.

[65] Reich T, Winokur G. Postpartum psychoses in patients with manic depressive disease. J Nerv Ment Dis 1970;151:60-8.

[66] Reiger DA, Myers JK, Kramer M, et al. The NIMH Epidemiological Catchment Area Program: Historical context, major objectives, and study population characteristics. Arch Gen Psychiatry 1984;41:934-41. 
[67] Ringstrom SJ, Suter DE, Hostetler JP, et al. Cortisol regulates secretion and pituitary content of the two gonadotropins differentially in female rats: Effects of gonadotropinreleasing hormone antagonist. Endocrinology 1992;130:3122-8.

[68] Robins LN, Helzer JE, Weissman MM, et al. Lifetime prevalence of specific psychiatric disorders in three sites. Arch Gen Psychiatry 1984;41:949-58.

[69] Rubin RT, Poland RE, Lesser IM, et al. Neuroendocrine aspects of primary endogenous depression I. Cortisol secretory dynamics in patients and matched controls. Arch Gen Psychiatry 1987;44:328-36.

[70] Rubin RT, Poland RE, Lesser IM. Neuroendocrine aspects of primary endogenous depression VIII. Pituitary-gonadal axis activity in male patients and matched control subjects. Psychoneuroendocrinology 1989;14:217-29.

[71] Rubinow DR, Schmidt PJ. Models for the development and expression of symptoms in premenstrual syndrome. Psychiatr Clin North Am 1989;12:653-81.

[72] Rupprecht R, Rupprecht C, Rupprecht M, et al. Different reactivity of the hypothalamopituitary-gonadal axis in depression and normal controls. Pharmacopsychiatry 1988;21: 438-9.

[73] Russel GFM, Beardwood CJ. Amenorrhea in feeding disorders: anorexia nervosa and obesity. Psychother Psychosom 1970;18:359-64.

[74] Sachar EJ, Hellman L, Roffwarg HP, et al. Disrupted 24-hour patterns of cortisol secretion in psychotic depressives. Arch Gen Psychiatry 1973;28:19-24.

[75] Sakakura M, Takebe K, Nakagawa S. Inhibition of leutenizing hormone secretion induced by synthetic LRH by long term treatment with glucocorticoids in human subjects. J Clin Endocrinol Metab 1975;40:774-9.

[76] Saketos M, Sharma N, Santoro NF. Suppression of the hypothalamic-pituiatry-ovarian axis in normal women by glucocorticoids. Biol Reprod 1993;49:1270-6.

[77] Samuels MH, Luther M, Henry P, Ridgeway EC. Effects of hyocortisone on pulsatile pituitary glycoprotein secretion. J Clin Endocrinol Metab 1994;78:211-315.

[78] Schmidt PJ, Nieman L, Danaceau MA, et al. Estrogen replacement in perimenopauserelated depression: A preliminary report. Am J Obstet Gynecol 2000;183:414-20.

[79] Schmidt PJ, Nieman LK, Grover GN, et al. Lack of effect of induced menses on symptoms in women with premenstrual syndrome. N Engl J Med 1991;324:1174-9.

[80] Schwartz N, Justo S. Acute changes in serum gonadotropins and steroids following orchidectomy in the rat: Role of the adrenal gland. Endocrinology 1977;100:1550-6.

[81] Schweiger U, Deuschle M, Weber B, et al. Testosterone, gonadotropin and cortisol secretion in male patients with major depression. Psychosom Med 1999;61:292-6.

[82] Suh BY, Liu JH, Berga SL, et al. Hypercortisolism in patients with functional hypothalamic-amenorrhea. J Clin Endocrinol Metab 1988;66:733-739.

[83] Sutter DE, Schwartz NB. Effect of glucocorticoids on secretion of luteinizing hormone and follicle-stimulating hormone by female rat pituitary cells in vitro. Endocrinology 1985; 117:849-54.

[84] Unden F, Ljunggren JG, Beck-Friis J, et al. Hypothalamic-pituitary-gonadal axis in major depressive disorders. Acta Psychiatr Scand 1988;78:138-46.

[85] Vale W, Spiess J, Rivier J, et al. Characterization of a 41-residue ovine hypothalamic peptide that stimulates secretions of corticotropin and beta-endorphin. Science 1981;213:1394-7.

[86] Villanueva AL, Schlosser C, Hopper B, et al. Increased cortisol production in women runners. J Clin Endocrinol Metab 1986;63:133-6.

[87] Weissman M, Klerman GL. Sex differences and the epidemiology of depression. Arch Gen Psychiatry 1977;34:98-111.

[88] Winokur A, Amsterdam J, Caroff S, et al. Variability of hormonal responses to a series of neuroendocrine challenges in depressed patients. Am J Psychiatry 1982;139:39-44.

[89] Winokur G, Clayton P. Family Studies: I. Two types of affective disorders separated according to genetic and clinical factors. In: Wortis IJ, editor. Recent Advances in Biological Psychiatry. New York: Plenum Press; 1967. 
[90] Xiao E, Ferin M. The inhibitory action of corticotropin-releasing hormone in the ovariectomized rhesus monkey is not mediated by ACTH. Biol Reprod 1988;38:763-76.

[91] Xiao E, Luckhaus J, Niemann W, et al. Acute inhibition of gonadotropin secretion by corticotropin-releasing hormone in the primate: are the adrenal glands involved? Endocrinology 1989;124:1632-7.

[92] Yonkers KA, Bradshaw KD. Hormone replacement and oral contraceptive therapy: Do they induce or treat mood symptoms. In: Gender Differences in Mood and Anxiety Disorders, From Bench to Bedside. Leibenluft E (ed). Washington, DC: American Psychiatric Press; 1999. p. 91-136.

[93] Young EA. Haskett RF, Watson SJ, et al. Loss of glucocorticoid fast feedback in depression. Arch Gen Psychiatry 1991;48:693-9.

[94] Young EA, Midgley AR, Carlson NE, et al. Alteration in the Hypothalamic-PituitaryOvarian axis in depressed women. Arch Gen Psychiatry 2000;57:1157-62.

[95] Young EA, Watson SJ, Kotun J, et al. Response to low dose oCRH in endogenous depression: Role of cortisol feedback. Arch Gen Psychiatry 1990;47:449-57. 